\title{
A Family History Study of Asperger Syndrome
}

\author{
Mohammad Ghaziuddin
}

\begin{abstract}
Asperger syndrome (AS) is a childhood-onset disorder often described as a mild variant of autism. Although classified as a distinct disorder in the DSM-IV, its overlap with autism continues to be a matter of ongoing debate. While the family genetic origins of autism are well established, few studies have investigated this topic in AS using current operational criteria. In this report, we examined the family psychiatric history of 58 subjects with AS diagnosed according to DSM-IV criteria (48 males; mean age 13.34; mean full scale IQ 104.87). All subjects had a history of mild autistic social deficits; focused special interests; normal level of intelligence; and an odd and often pedantic manner of speaking. None had a previous diagnosis of autism. Of the 58 subjects with Asperger syndrome, three had first degree relatives with AS; nine (15\%) had a family history of schizophrenia; and $35(60 \%)$ had a family history of depression. Of the 64 siblings, four had a diagnosis of AS and none of autism. Compared with a group of 39 subjects with normal intelligence autism (high functioning autism, HFA; 33 males; mean age 15.34; mean full scale IQ 85.89) subjects with AS were more likely to have relatives with depression; schizophrenia; and the broader autistic phenotype. Possible reasons for and implications of these findings are discussed.
\end{abstract}

KEY WORDS: Asperger syndrome; autism; depression; schizophrenia; family history; genetics.

\section{INTRODUCTION}

Asperger syndrome (AS) is a type of pervasive developmental disorder characterized by autistic social dysfunction; focused interests; and subtle communication deficits occurring in the presence of normal intelligence. There is no history of formal speech delay. Introduced only about a decade back in the DSM-IV (APA, 1994), it is being diagnosed with increasing frequency. Its prevalence estimates have ranged from 2.5 per 10,000 (Fombonne \& Tidmarsh 2003) to as high as 7 per 1000 (Ehlers \& Gillberg 1993). In contrast, the prevalence of autism is usually given as 4 per 10,000 and that of the broader autistic phenotype as 4 per 100 (Folstein \& Santangelo, 2000).

Division of Child Psychiatry, University of Michigan Medical Center, Ann Arbor, MI, 48109-0277, USA; e-mail: mghaziud@, umich.edu
Although Asperger syndrome is widely believed to cluster in families, few systematic studies have investigated its family genetic aspects. Evidence for its genetic origin comes from case reports and studies of probands with classic autism, not those of probands with Asperger syndrome. For example, in a family history study of autism, out of 137 siblings of autistic probands, only one was diagnosed with Asperger syndrome (Bolton et al., 1994). Compared to a control group of siblings with Down syndrome, 5.8\% in the autism group were diagnosed with autism, atypical autism or Asperger syndrome, compared to $0 \%$ in the Down syndrome group (none out of 64 siblings with Down syndrome). In contrast to Asperger syndrome, evidence for the familial loading of autism is well-established. In addition to carrying a high risk for autistic disorder, close relatives of subjects with autism show a preference for solitariness; deficits of social and narrative language; a resistance to change; a desire for sameness; and mild deficits of executive 
functioning (Bailey et al., 1995; Piven et al., 1994). Sometimes referred to as the broader autistic phenotype (BAP) or the lesser variant, these deficits are not severe enough to justify the full diagnosis of autism. In order to investigate the familial aspects of $\mathrm{AS}$ and determine its degree of relatedness to autism, it is important to perform studies focusing on large series of probands with AS (Spiker, Lotspeich, Dimiceli, Myers, \& Risch, et al., 2002). The purpose of this study is to address this issue.

Two main reasons account for the paucity of findings on the familial aspects of Asperger syndrome. First, studies have not used standardized criteria for the diagnosis of AS. A decade after the inclusion of the disorder in the DSM classificatory system, studies continue to use modified criteria or include subjects with both autism and Asperger syndrome (Ghaziuddin, Tsai, \& Ghaziuddin, 1992; Miller and Ozonoff, 1997). The problem is partly confounded by the manner in which the criteria are currently formalized (see Gillberg, 1998). Second, the boundaries of AS are not clearly demarcated. Earlier assertions of a clear distinction between autism and Asperger syndrome have so far proved specious. Indeed, Asperger syndrome needs to be separated not only from autism but also from PDDNOS; the broader autism phenotype (BAP) or the lesser variant of autism; and from schizoid/schizotypal personality disorders. The latter distinction is particularly important because of the known association of these conditions with schizophrenia (Kendler et al., 1993). Thus, research focusing on the familial aspects of AS can shed light on its relationship not only with autism but also with related conditions.

Asperger himself believed that the condition was strongly genetic in nature, and that fathers of patients that he described were often highly intelligent. Among the 200 children he saw over a period of 10 years, almost all had at least one parent with similar personality traits (Asperger, 1944). Subsequent studies on this topic also emphasized its genetic roots. In particular, Van Krevelan (1971), one of the earlier researchers who attempted to carve out Asperger syndrome from autism, proposed that the condition was over-represented in the fathers of children with AS and that, to a large extent, was passed down from fathers to sons. He suggested that Asperger syndrome was more genetical-based than autism (1971). Although more recent research has not specifically investigated Van Krevelan's hypothesis, it is nonetheless believed that AS, like autism, is a strongly genetic disorder. Wing (1981) found that out of 34 cases, 5 of the 16 fathers and 2 of the 24 mothers, showed behavioral traits resembling those of Asperger syndrome. In Gillberg's series of 23 patients with Asperger syndrome, several of the parents showed similar personality traits (Gillberg, 1989). In Wolff's series, out of 32 male patients, 7 fathers and 12 mothers had similar traits, compared to one mother and no father in the 32 males in the control group. Among 33 girls similarly examined, only one mother and four fathers were definitely affected compared to two mothers and two fathers in the control group (Wolff \& McGuire, 1995). A few case reports have also been published describing the familial clustering of Asperger syndrome. Ghaziuddin, Metler, Ghaziuddin, Tsai, \& Giordani et al. (1993) described a family in which the father had features of schizoid personality disorder and his three sons had a diagnosis of Asperger syndrome. Volkmar et al. (1996) described a 15-year-old youngster with Asperger syndrome. Both the proband and his father showed discrepancies between the verbal IQ and the performance IQ, with the verbal abilities being higher. The proband displayed a split of 50 points on the verbal performance IQ (verbal IQ 140, performance IQ 90), and the father showed a split of 43 points (verbal 129, performance 86). Deficits in the social use of language and on MRI examination were also found. In the discussion of their paper, the authors stated that the major reasons for including Asperger syndrome as a diagnostic entity in the DSM-IV system of classification rested "both on its differentiation from autism and the apparently higher frequency of transmission of this condition within families" (Volkmar et al., 1996). However, what is meant by a higher frequency of transmission has not been spelled out. The present study was, therefore, undertaken to clarify the pattern of familial aggregation of subjects with Asperger syndrome with reference to the presence of autism spectrum disorders and major psychiatric disorders in the first degree relatives.

\section{METHOD}

Subjects were referred to the author over a period of 5 years, and were derived from community sources, such as mental health centers and schools, and psychiatric clinics. For inclusion in the study, subjects had to have a diagnosis of a pervasive developmental disorder; a full scale IQ of 70 or above on an individually administered test of intelligence; and the presence of at least one biological parent. 
Consistent with the recommendations of the DSM-IV (APA, 1994), a heirarchical approach was used to diagnose AS. If the subject met the criteria for a pervasive developmental disorder, he was considered for a diagnosis of autism. If the subject did not meet the full criteria for autism, he was considered for a diagnosis of Asperger syndrome. (If the criteria for both autistic disorder and Asperger syndrome were not met with, then a diagnosis of PDDNOS was given.) For a diagnosis of autism, the subject was required to meet all the requisite criteria based on the DSM-IV (APA, 1994). For the diagnosis of Asperger syndrome, subjects were required to have autistic social dysfunction; strong isolated interests; lack of language delay; and lack of mental retardation. Language delay was defined as the absence of at least three-word phrase speech by 3 years of age. Mental retardation was defined as the presence of IQ below 70 along with deficits of adaptive functioning.

No attempt was made to define whether or not a subject with AS showed a normal level of curiosity about the environment in his early childhood, or had evidence of motor clumsiness, since these features, though often present in AS, are not essential for its diagnosis (APA, 1994). Categorization of the BAP was done on the basis of what has been described in the literature. To be labeled as suffering from BAP or the lesser variant, the individual must have a history of social deficits and/or rigid ritualistic interests and/ or a history of language delay, severe articulation disorder, and pronounced reading retardation (Bolton et al., 1994; Piven et al., 1994). Subjects under the age of 7 years were excluded because, in the author's view, focused interests typical of AS do not often develop before this age. In addition, subjects who were adopted or those who did not have at least one biological parent for interview were excluded.

The diagnostic process consisted of a detailed psychiatric interview, a neuropsychological examination, a speech and language assessment, and perusal of all available records. Collateral information from schools and other agencies was also collected. All cases were personally interviewed by the author (MG) either on the basis of the autism diagnostic interview (ADI, Le Couteur et al., 1989; Lord 1994), or with the autism behavior checklist (ABC, Krug, Arick, \& Almond et al., 1980). In most cases, subjects were seen at regular intervals over an extended period of time for follow-up treatment. Collection of family psychiatric history was based on the FH-RDC (Andreasen et al., 1977) and/or the Family History Schedule (Bolton et al., 1994). The latter instrument has been used to quantify the range of mild autistic deficits that occur in relatives of subjects with autism. For the purpose of this study, the FHS was shortened. The main focus of the interview was on the parents and siblings, although details about second and third degree relatives were also obtained.

\section{RESULTS}

\section{The Sample}

Sixty-three subjects were given a diagnosis of AS. Of these, one was adopted, two did not have a detailed history, and two were under the age of 7 years. The final sample, therefore, consisted of 58 AS subjects.

Forty-five subjects received a diagnosis of autism in the presence of normal intelligence (high functioning autism, HFA). Of these, five were excluded because they were adopted, and one subject was excluded because he was under 7 years of age. The final number of HFA subjects eligible for the study was, therefore, 39.

As a group, AS subjects had a higher full scale IQ than the HFA group (AS mean full scale $\mathrm{IQ}=104.8 ; \quad$ HFA mean full scale $\mathrm{IQ}=89.8$; $p \leq .001)$. AS subjects also had higher verbal and performance IQs than the HFA subjects (AS mean verbal IQ $=107.8$; HFA mean verbal IQ $=86.8$; $p \leq 0.0001$ ); and higher performance IQ (AS mean 100.2; HFA 87.4) (Table I).

\section{Familial Aggregation of Autism/Asperger Syndrome}

Of the 58 subjects with AS, three had a positive family history of AS. In one case, the father met the criteria for Asperger syndrome. In the second case, a sibling was diagnosed with AS, while in the third case, two siblings had a diagnosis of AS. Also, two of the subjects with Asperger syndrome had third degree relatives (cousins) with autism (one subject had a cousin with autism, and another had two cousins with autism). In addition, 17 (29\%) subjects with Asperger syndrome gave a history of the lesser variant of autism (BAP) in their relatives.

Of the 39 subjects with high functioning autism (HFA group), a family history of autism was present in four subjects; that of AS in one subject; and the BAP in eight subjects. Also, a history of autism was present in three third degree relatives (cousins). None 
Table I. Familial Aggregation of Asperger Syndrome

\begin{tabular}{lcc}
\hline & $\begin{array}{l}\text { Asperger syndrome } \\
(n=58)\end{array}$ & $\begin{array}{l}\text { High functioning } \\
\text { autism }(n=39)\end{array}$ \\
\hline Mean age (SD) & $13.34(7.90)$ & $15.33(7.2)$ \\
Males:females & $48: 10$ & $33: 6$ \\
Mean verbal IQ (SD) & $107.82(17.86)$ & $86.89(16.32)$ \\
Mean performance IQ (SD) & $100.22(18.11)$ & $87.40(17.39)$ \\
Mean full scale IQ (SD) & $104.87(16.30)$ & $85.89(16.31)$ \\
FH of Asperger syndrome & $3(5 \%)$ & $1(2.5 \%)$ \\
FH of autism & $2(3.4 \%)$ & $4(10.2 \%)$ \\
FH of BAP & $17(29 \%)$ & $8(20.5 \%)$ \\
FH of schizophrenia & $9(15.5 \%)$ & $4(10.2 \%)$ \\
FH of depression & $35(60.3 \%)$ & $20(51.2 \%)$ \\
\hline
\end{tabular}

of the second or third degree relatives in this group had a history of Asperger syndrome.

Of a total of 64 siblings in the AS group, four had a diagnosis of AS (two of these were siblings). None of the siblings in the AS group, however, had a diagnosis of autism. The HFA group contained 50 siblings. One of these had a history of autism and there were none with AS. Thus, of the 114 siblings combined in both the AS and HFA groups, therefore, $5(4.3 \%)$ suffered from either autism or AS.

\section{Other Conditions}

Thirty-five subjects with AS had a family history of depression. In the HFA group, 20 subjects had a family history of depression. Eight subjects with AS had a family history of schizophrenia compared to three in the HFA group. Of the eight in the AS group, four were first degree relatives, while one in the HFA group was a first degree relative. None of these differences, however, reached statistical significance.

\section{DISCUSSION}

The present study supports the view that Asperger syndrome clusters in families. In addition, it provides preliminary data about the prevalence of other psychiatric disorders, such as depression and schizophrenia, in the relatives of subjects with Asperger syndrome. Out of 64 siblings of AS probands, four met the criteria for autism (two of these were siblings). Thus, counting the sibling pair as one sibling, three met the diagnosis of AS which gives a frequency of $4.6 \%$. None of the siblings in the AS group had a diagnosis of autism. When siblings of both AS and HFA were combined, of the 114 siblings, five (4.3\%) were diagnosed with either autism or
AS. However, these rates can only be regarded as preliminary because similar studies have not been done on probands with AS using current diagnostic criteria.

Family genetic studies of children with autism have shown the co-aggregation with Asperger syndrome. For example, in the Bolton et al. study, four (2.9\%) of the 137 siblings of autistic probands met the criteria for autism, and a further four $(2.9 \%)$ were classified as having other forms of pervasive developmental disorders. Three were classified as having atypical autism and one with Asperger syndrome (Bolton et al., 1994). Thus, 5.8\% of the siblings of autistic probands were diagnosed as having autism, Asperger syndrome or atypical autism. In the present study, the high functioning autistic (HFA) group contained 50 siblings. Only one (2\%) of these had a history of autism and none with AS. These findings are different, in part, because, by design, it focused only on high-functioning people with autism. The Bolton et al. study, on the other hand, included patients of a wide range of intellectual ability.

It has been suggested that AS is more "strongly genetic" than autism. Case series have described the occurrence of AS-like features in family members especially in fathers and grandfathers (Van Krevelan, 1971). Some authorities have suggested that the "strongly genetic" nature of AS may be one way in which this condition differs from autism (Van Krevelan, 1971; Volkmar et al., 1996). In the present study, more family members of AS subjects showed features of the broader autistic phenotype (that is, mild autistic features without meeting the criteria of any specific PDD) than family members of autistic subjects. About $29 \%$ of AS subjects had family members with the BAP compared to $20 \%$ in the HFA group, a difference that did not reach statistical significance. These findings lend limited support to the 
view that $\mathrm{AS}$ is more strongly genetic than traditional autism, although no firm conclusions can be drawn.

Several family members in the AS group gave a history of depression and other mood disorders. Studies have found an excess of mood and anxiety disorders in the parents of subjects with autism (for example, Piven \& Palmer, 1991; Piven et al., 1991) compared to parents of subjects with other developmental disorders such as Down syndrome, implying a specific relationship between autism and mood/anxiety disorders. Preliminary studies have also described the occurrence of depression and other mood disorders in persons with Asperger syndrome, especially in adolescence (Ghaziuddin et al., 1998). In a more recent study, Gillberg and colleagues found that out of a sample subjects with autism spectrum disorders, including those with $\mathrm{AS}, 7 \%$ had bipolar disorder with psychotic features and $7.8 \%$ had schizophrenia and other psychotic disorders (Stahlberg, Soderstrom, Rastam, \& Gillberg 2004). The present study extends these findings to the parents, and suggests that parents of subjects with AS also appear to be at an increased risk of mood disorders. Other studies, using modified diagnostic criteria for Asperger syndrome, have found higher rates of bipolar disorder in relatives of patients with Asperger syndrome (Delong, 1994). In the present study, no such association was found, probably because of the differences in the diagnostic criteria used.

An unexpected finding of the study was the rather high rate of schizophrenia found in both the AS and the autistic groups, especially in the former. Of a combined sample of 97 subjects (AS plus HFA), $13(14 \%)$ subjects had a history of schizophrenia. 15\% of AS and 10\% HFA subjects had a family history of schizophrenia. Although autism and schizophrenia share a historical relationship, they are generally regarded as two distinct disorders (Rutter, 1972; Petty et al., 1984). However, some patients with autism may show superficial similarities to schizophrenia. For example, patients with chronic schizophrenia may resemble those with autism, especially in adults, a fact that is underscored by the mistaken diagnosis of negative schizophrenia in adults with autism attending community mental health centers. Patients with AS may also resemble those with schizophrenia, especially those with positive schizophrenia. They may appear disorganized and tangential in their thinking, with overvalued ideas and a tendency to fixate on their internal life (Dykens, Volkmar, \& Glick 1991; Ghaziuddin, Leininger, \& Tsai, et al., 1995). Some of them develop brief psychotic episodes of unknown cause, while others develop psychotic behavior in the setting of mood disorders.

Studies have shown common genetic mechanisms in the etiology of schizophrenia and schizoid/ schizotypal personality disorders. About a quarter of schizophrenic patients have had a history of schizoid or schizotypal personalities before the onset of their illness. Among biological relatives of schizophrenic patients, the proportions with schizotypal personality disorder have varied from 5\% among all relatives (Kendler et al., 1993) to about $20 \%$ for the children of mothers with schizophrenia (Parnas et al., 1993). Despite the superficial resemblance between some autism spectrum disorders and schizoid/schizotypal personality disorders, relatively little is known about the developmental aspects of the latter. Some authors have suggested that schizoid personality disorder overlaps with Asperger syndrome. In Wolff's sample of follow-up of children with schizoid personality disorder, 5\% developed schizophrenia, a rate that is 12 times the expected rate (Wolff \& Chick, 1980). In the present study, nine AS and five HFA subjects had a family history of schizophrenia. These findings raise the possibility that some patients with high functioning autism spectrum disorders may be at an increased risk to the development of schizophrenia. To summarize, subjects with Asperger syndrome tended to show an excess of AS in their families and a trend towards an excess of relatives with schizophrenia; depression; and the broader autistic phenotype, compared to controls with autism. However, because of the small sample size and the method of recruitment, more research based on community samples is needed before any firm conclusions can be drawn.

\section{REFERENCES}

American Psychiatric Association (1994). Diagnostic and statistical manual of mental disorders: Fourth edition. Washington: APA.

Andreasen, N.C., Endicott, J., Spitzer, R.L. \& Winokur, G. (1977). The family history method using diagnostic criteria. Reliability and validity. Archives of General Psychiatry, 34 (10), 1229-1235.

Asperger, H. (1944). Die autistischen Psychopathen im Kindersalter Archiv fur Psychiatrie und Nervenkrankheiten, 117, 76136.

Bailey, A., Le Couteur, A., Gottesman, I., Bolton, P., Simonoff, E., Yuzda, E., \& Rutter, M. (1995). Autism as a strongly genetic disorder: Evidence from a British twin study Psychological Medicine, 25(1), 63-77.

Bolton, P., Macdonald, H., Pickles, A., Rios, P., Goode, S., Crowson, M., Bailey, A., \& Rutter, M. (1994). A case-control family history study of autism Journal of Child Psychology and Psychiatry, 35(5), 877-900. 
Dykens, E., Volkmar, F., \& Glick, M. (1991). Thought disorder in high-functioning autistic adults Journal of Autism and Developmental Disorders, 21, 291-301.

Ehlers, S., \& Gillberg, C. (1993). The epidemiology of Asperger syndrome. A total population study. Journal of Child Psychology and Psychiatry, 34(8), 1327-1350.

Fombonne, E., \& Tidmarsh, L. (2003). Epidemiologic data on Asperger disorder Child and Adolescent Psychiatric Clinics of North America, 12(1), 15-21.

Folstein, S., \& Santangelo, S. L. (2000). Does Asperger syndrome aggregate in families? In A. Klin, F. Volkmar, \& S. S. Sparrow (Eds.) Asperger syndrome. New York: Guliford Press.

Ghaziuddin, M., Tsai, L., \& Ghaziuddin, N. (1992). A comparison of the diagnostic criteria for Asperger syndrome Journal of Autism and Developmental Disorders, 22(4), 643-649.

Ghaziuddin, N., Metler, L., Ghaziuddin, M., Tsai, L., \& Giordani, B. (1993). Three siblings with Asperger syndrome: A family case study European Child and Adolescent Psychiatry, 2(1), 44- 49.

Ghaziuddin, M., Leininger, L., \& Tsai, L. (1995). Thought disorder in Asperger syndrome: Comparison with high-functioning autism Journal of Autism and Developmental Disorders, 25(3), 311-317.

Ghaziuddin, M., Weidmer-Mikhail, E. and Ghaziuddin, N. (1998). Comorbidity of Asperger syndrome: a preliminary report. Journal of Intellectual Disability Research, 42 (4), 279-283.

Gillberg, C. (1989). Asperger syndrome in 23 Swedish children Developmental Medicine and Child Neurology, 31, 520-531.

Gillberg, C. (1998). Asperger syndrome and high-functioning autism British Journal of Psychiatry, 172, 200-209.

Kendler, K. S., McGuire, M., Gruenberg, A. M., O'Hare, A., Spellman, M., \& Walsh, D. (1993). The Roscommon family study: III Schizophrenia-related personality disorders in relatives Archives of General Psychiatry, 50, 781-788.

Krug, D. A., Arick, J., \& Almond, P. (1980). Behavior checklist for identifying severely handicapped individuals with high levels of autistic behavior Journal of Child Psychology and Psychiatry, 21, 221-229.

Le Couteur, A., Rutter, M., Lord, C., Rios, P., Robertson, S., Holdgrafer, M., \& McLennan, J. (1989). Autism diagnostic interview: A standardized investigator-based instrument. Journal of the Austim and Developmental Disorders, 19(3), 363387.

Lord, C., Rutter, M., \& Le Couteur, A. (1994). Autism diagnostic interview - revised: A revised version of a diagnostic interview for caregivers of individuals with possible pervasive developmental disorders Journal of Autism and Developmental Disorders, 24, 659-685.

Miller, J. N., \& Ozonoff, S. (1997). Did Asperger's cases have Asperger disorder? A research note Journal of Child Psychology and Psychiatry, 38, 247-251.
Parnas, J., Cannon, T. D., Jacobsen, B., Schulsinger, H., Schulsinger, F., \& Mednick, S. A. (1993). Lifetime DSM-III-R diagnostic outcomes in the offspring of schizophrenic mothers: Results from the Copenhagen high-risk study Archives of General Psychiatry, 50, 707-714.

Petty, L. K., Ornitz, E. M., Michelman, J. D., \& Zimmerman, E. G. (1984). Autistic children who become schizophrenic Archives of General Psychiatry, 41(2), 129-35.

Piven, J., Chase, G. A., Landa, R., Wzorek, M., Gayle, J., Cloud, D., \& Folstein, S. (1991). Psychiatric disorders in the parents of autistic individuals Journal of the American Academy of Child and Adolescent Psychiatry, 30, 471-478.

Piven, J., Wzorek, M., Landa, R., Lainhart, J., Bolton, P., Chase, G. A., \& Folstein, S. (1994). Personality characteristics of the parents of autistic individuals Psychological Medicine, 24(3), 783-795.

Piven, J., \& Palmer, P. (1999). Psychiatric disorder and the broad autism phenotype: Evidence from a family study of multipleincidence autism families. American Journal of Psychiatry, 156(4), 557-563.

Rutter, M. (1972). Childhood schizophrenia reconsidered Journal of Autism and Childhood Schizophrenia, 2, 315-337.

Spiker, D., Lotspeich, L. J., Dimiceli, S., Myers, R. M., \& Risch, (2002). Behavioral phenotypic variation in autism multiplex families: Evidence for a continuous severity gradient American Journal of Medical Genetics (Neuropsychiatric Genetics), 114, $129-136$.

Stahlberg, O., Soderstrom, H., Rastam, M., \& Gillberg, C. (2004). Bipolar disorder, schizophrenia, and other psychotic disorders in adults with childhood onset $\mathrm{AD} / \mathrm{HD}$ and/or autism spectrum disorders Journal of Neural Transmission, 111(7), 891902.

Krevelen, D. A. (1971). Early infantile autism and autistic psychopathy Journal of Autism and Childhood Schizophrenia, 1, $82-86$.

Volkmar, F., Klin, A., Schultz, R., Bronen, R., Marans, W. D., Sparrow, S., \& Cohen, D. J. (1996). Asperger's Syndrome Journal of the American Academy of Child and Adolescent Psychiatry, 35(1), 118-1123.

Wing, L. (1981). Asperger's syndrome: A clinical account Psychological Medicine, 11, 115-129.

Wolff, S., \& Chick, J. (1980). Schizoid personality in childhood: A controlled follow-up study Psychological Medicine, 10, 85100 .

Wolff, S., \& McGuire, R. J. (1995). Schizoid personality in girls: A follow-up study-What are the links with Asperger's syndrome? Journal of Child Psychology and Psychiatry, 36(5), $793-817$. 